\title{
PRODUÇÃO DE DOCE DE LEITE COM TEOR REDUZIDO DE LACTOSE POR $\beta$-GALACTOSIDASE
}

\author{
Doce de leite production with $\beta$-galactosidase for individuals \\ with lactose intolerance
}

\author{
Karina Mota Martins Moreira ${ }^{[a]}$, Linnae Hoffmann Coelho ${ }^{[a]}$, Carla Corradi Perini ${ }^{[a]}$, \\ Márcia Rapacci ${ }^{[b]}$, Laura Beatriz Karam ${ }^{[c]}$
}

\footnotetext{
[a] Nutricionista, Departamento de Nutrição da Pontifícia Universidade Católica do Paraná (PUCPR), Curitiba, PR - Brasil, e-mail: karininha_m@yahoo.com.br,linnaecoelho@hotmail.com, carla.corradi@pucpr.br

${ }^{[b]}$ Química'Departamento de Engenharia de Alimentos da Pontifícia Universidade Católica do Paraná (PUCPR), Curitiba, PR Brasil, e-mail: rapacci.m@pucpr.br

${ }^{[c]}$ Engenheira de Alimentos, Departamento de Engenharia de Alimentos e Programa de Pós-graduação em Ciência Animal da Pontifícia Universidade Católica do Paraná (PUCPR), Curitiba, PR - Brasil, e-mail: laura.karam@pucpr.br
}

\section{Resumo}

A intolerância à lactose é uma inabilidade para digerir completamente a lactose, o açúcar predominante do leite. Tal fato se torna preocupante, pois essa condição afeta mais de $75 \%$ da população mundial. O objetivo deste trabalho foi propor a produção de um doce de leite com teor reduzido de lactose, testando duas marcas comerciais da $\beta$-galactosidase. Os doces de leite foram submetidos às análises físicas, químicas e sensoriais. Nos testes preliminares verificou-se que o grau de hidrólise total da lactose presente no leite, na concentração de $0,8 \mathrm{~g}$ de $\beta$-galactosidase por litro de leite, foi atingido em 6 horas. No doce de leite, os níveis de lactose foram inferiores ao limite de quantificação $(\leq 0,5 \%)$, podendo ser considerado com teor reduzido de lactose. Pelo teste sensorial de comparação múltipla, as enzimas $\beta$-galactosidase de ambas as marcas não apresentaram diferença significativa (em nível de 5\%) com relação ao sabor do produto, quando comparadas com o padrão, sem o uso da enzima. Já a coloração escura dos doces produzidos com leite tratado com a enzima $\beta$-galactosidase foi atribuída à intensificação da reação de Maillard no pH 6,0 e à hidrólise da lactose com a maior disponibilização de açúcares redutores. A composição centesimal média dos doces de leite produzidos foram $26,9 \%$ de umidade, $6,8 \%$ de gordura, $8,6 \%$ de proteína, 55,8\% de carboidratos e $1,7 \%$ de cinzas. Pode-se concluir que os doces de leite produzidos com as diferentes marcas da enzima $\beta$-galactosidase podem ser consumidos por portadores intolerantes à lactose.

Palavras-chave: Doce de leite. Redução da lactose. $\beta$-galactosidase.

Rev. Acad., Ciênc. Agrár. Ambient., Curitiba, v. 7, n. 4, p. 375-382, out./dez. 2009 


\begin{abstract}
The lactose intolerance is an inability to fully digest lactose, the predominant sugar of milk. That's a concern because this condition affects more than $75 \%$ of world population. The aim of this work was to propose the production of doce de leite with reduced lactose content, testing two marks of commercial $\beta$-galactosidase. Doce de leite was subjected to physical, chemical and sensory analysis. In preliminary tests it was found that the degree of lactose's total hydrolysis in milk, at a concentration of $0.8 \mathrm{~g}$ of $\beta$-galactosidase per liter of milk, was reached in 6 hours. In doce de leite, the lactose levels were below the limit of quantification $(\leq 0.5 \%)$, thus can be considered as low level of lactose. At the sensory test of multiple comparison, $\beta$-galactosidase enzyme in both brands of milk showed no significant difference (in level of 5\%) when compared with the standard taste of the product, without using the enzyme. The darker color of doce de leite produced with the enzyme $\beta$-galactosidase is due to the Maillard reaction, intensified in $\mathrm{pH}$ 6.0 , and to lactose's hydrolysis initially present in milk, which released more reducing sugars to take part of this reaction, during the production of doce de leite. The average composition of the produced doce de leite was $26.9 \%$ moisture, $11.3 \%$ fat, $8.6 \%$ protein, $51.4 \%$ carbohydrate and $1.7 \%$ ash. It can be concluded that the doce de leite produced with different brands in the $\beta$-galactosidase enzyme can be consumed by the lactose intolerant individuals.
\end{abstract}

Keywords: Doce de leite. Lactose reduction. $\beta$-galactosidase.

\title{
INTRODUÇÃO
}

A intolerância à lactose é uma inabilidade do organismo para digerir completamente a lactose, o açúcar predominante do leite, decorrente da queda da atividade da $\beta$-galactosidase na mucosa intestinal (TÉO, 2002). Essa condição afeta mais de $75 \%$ da população mundial, dos quais aproximadamente 5\% ocorrem no norte da Europa, e mais de 90\% em alguns países da Ásia e da África (BULHÕES et al., 2007). No Brasil, estudos mostram prevalências de $8 \%$ a $45 \%$ nas regiões sudeste e sul (PRETTO et al., 2002; PEREIRA FILHO; FURLAN, 2004), com aumento significativo na região nordeste $(75 \%)$ (SPARVOLI, 1989).

A deficiência de $\beta$-galactosidase é geralmente diagnosticada com base em: história de sintomas gastrointestinais (dores e distensão abdominais, flatulência e diarreia) que ocorrem após ingestão do leite; teste para níveis anormais de hidrogênio na respiração; ou teste de tolerância à lactose (LOMER et al., 2008).

O tratamento da intolerância à lactose consiste basicamente na retirada ou diminuição desse açúcar da dieta, o que leva ao desaparecimento progressivo dos sintomas (SUAREZ; SAVAIANO, 1997). Tendo em vista que o leite é uma das principais fontes de lactose, pois ela representa 4,6\% dos seus sólidos totais, a quantidade desse alimento na dieta deve ser reduzida. Uma das grandes preocupações com a diminuição da lactose na alimentação é a garantia do fornecimento de quantidade apropriada de proteínas, cálcio, riboflavina e vitamina $\mathrm{D}$, que tem no leite e em seus derivados sua maior fonte (UGGIONI; FAGUNDES, 2006).

Observa-se que existem hoje no mercado produtos considerados substitutos ao leite de vaca, que são direcionados aos indivíduos intolerantes à lactose. A maioria desses produtos é produzida empregando-se a soja como matéria-prima. A substituição do leite de vaca por bebidas à base de soja seria uma alternativa nutricionalmente perfeita, se fosse considerada apenas a quantidade de proteína. No entanto, sabe-se que a soja tem uma quantidade significativamente menor de cálcio em sua composição quando comparada com o leite de vaca (CASÉ et al., 2005). 
Atualmente, no Brasil são comercializadas várias marcas de leite com teor reduzido de lactose; entretanto, há no mercado uma carência de produtos lácteos industrializados. Industrialmente emprega-se a enzima $\beta$-galactosidase, ou lactase de origem microbiana, para hidrolisar a lactose do leite. O leite com teor reduzido de lactose pode apresentar um decréscimo aproximado de até $95 \%$ no teor de lactose total (CUNHA; SOARES, 2007).

Produtos lácteos que apresentam teores reduzidos de lactose enquadram-se no regulamento técnico referente às informações sobre Alimentos para Fins Especiais, que podem ser definidos como "formulações ou processados, nos quais se introduzem modificações no conteúdo de nutrientes, adequados à utilização em dietas, diferenciadas ou opcionais, atendendo às necessidades das pessoas em condições metabólicas e fisiológicas especiais" (BRASIL, 1998).

De acordo com o Regulamento Técnico Mercosul para Fixação de Identidade e Qualidade, entende-se por doce de leite o produto, com ou sem a presença de outras substâncias alimentícias, obtido por concentração do leite e ação do calor, a uma pressão normal ou reduzida do leite ou leite reconstituído, com ou sem acrescentamento de sólidos de origem láctea e/ou creme, e adicionado de sacarose (BRASIL, 1997).

Visando a atender ao mercado de alimentos para fins especiais, este trabalho tem como objetivo propor a produção de um doce de leite com teor reduzido de lactose, empregando-se duas marcas comerciais da enzima $\beta$-galactosidase, disponibilizando um produto com características físicas, químicas e sensoriais similares ao doce de leite tradicional, direcionado aos indivíduos com intolerância à lactose.

\section{METODOLOGIA}

\section{Matéria-prima}

Os doces de leite foram formulados empregando-se leite integral, contendo 3,5\% de gordura $(\mathrm{p} / \mathrm{v})$, previamente pasteurizado e homogeneizado; bicarbonato de sódio, para correção da acidez do leite, e açúcar refinado. Para hidrólise da lactose, utilizou-se a enzima $\beta$-galactosidase de duas marcas comerciais (Prozyn e Novozymes), ambas produzidas por fermentação submersa da Kluyveromyces lactis e com atividade enzimática de $3000 \mathrm{LAU} / \mathrm{mL}$.

\section{Grau de hidrólise enzimática}

Ao leite resfriado a $7^{\circ} \mathrm{C}$ adicionou-se $0,8 \mathrm{~g}$ da enzima $\beta$-galactosidase por litro de leite. Alíquotas de $200 \mathrm{~mL}$ de leite adicionado de $\beta$-galactosidase foram submetidas à fervura por 15 minutos em banho-maria, para inativação enzimática, e o grau de hidrólise ( $\mathrm{GH} \%)$ foi calculado nos tempos 0 , 6, 12, 18, 24, 30 e 36 horas pelo índice crioscópico, aplicando-se a Equação 1.

$$
G H=(350,877 x \text { Crioscopia Final })-(\text { Crioscopia Inicial / 0,00285 })
$$

\section{Produção do doce de leite}

O doce de leite foi fabricado conforme o diagrama de fluxo apresentado na Figura 1. Três formulações de doce de leite foram produzidas; uma com leite contendo lactose (amostra padrão) e outras duas tratadas com as diferentes marcas comerciais da enzima $\beta$-galactosidase (Prozyn e Novozymes). 


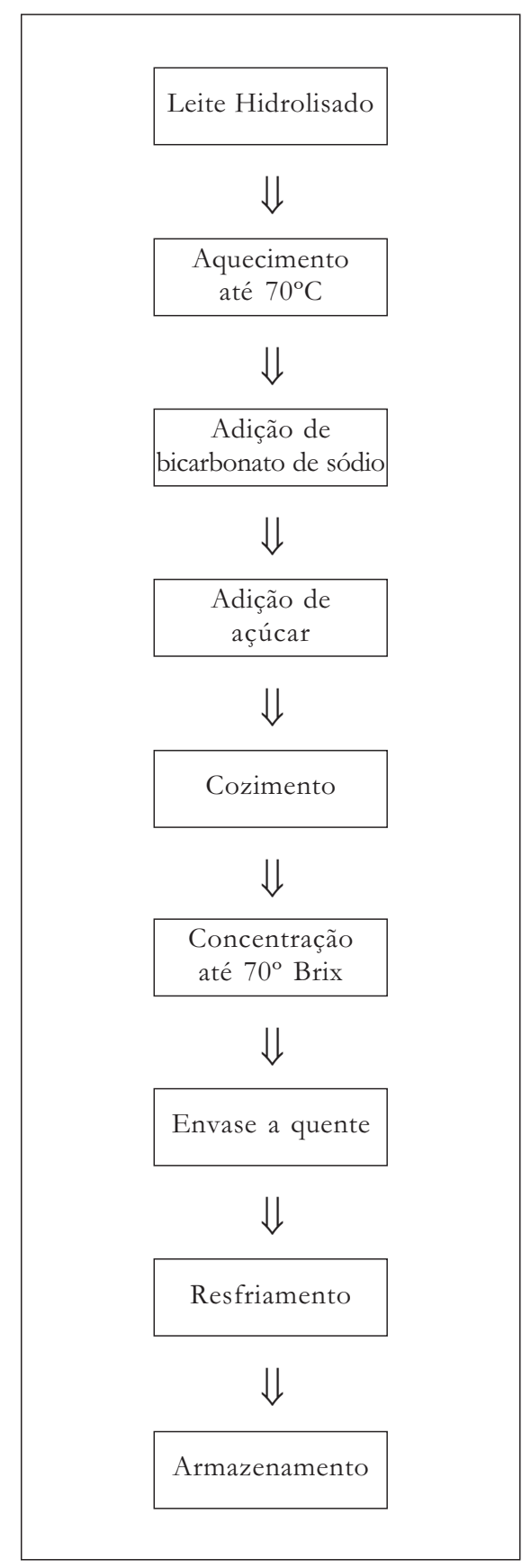

FIGURA 1 - Diagrama de fluxo da fabricação do doce de leite

\section{ANÁLISE CENTESIMAL DO DOCE DE LEITE}

As formulações de doce de leite foram submetidas às seguintes determinações físicas e químicas: $\mathrm{pH}$, umidade, proteínas, gorduras, cinzas e carboidratos, incluindo a lactose. $\mathrm{O}$ pH foi realizado em potenciômetro digital (Marca INGOLD, modelo WTW - pH 91). Os teores de cinzas foram determinados em mufla regulada para temperatura em torno de $550^{\circ} \mathrm{C}$ (AOAC, 2000). O teor de umidade foi verificado pelo método gravimétrico, em estufa à temperatura entre $102^{\circ} \mathrm{C}$ e $104^{\circ} \mathrm{C}$ (INTERNATIONAL DAIRY FEDERATION, 1982). O teor de gordura foi determinado pelo método de Mojonnier, conforme AOAC (2000), e o de proteína total, pelo método de Kjeldahl, empregando-se o fator 6,38 (AOAC, 2000). O teor de lactose foi definido por cromatografia gasosa (AOAC, 2000).

\section{Análise sensorial do doce de leite}

Os doces de leite foram analisados quanto ao atributo sabor, empregando-se teste de comparação múltipla, utilizando uma escala estruturada numérica e verbal de 9 pontos, sendo: $1=$ extremamente melhor que o padrão, $5=$ igual ao padrão e $9=$ extremamente pior que o padrão, conforme Dutcosky (2007). Cada julgador recebeu quatro amostras de doce de leite, sendo uma escolhida como padrão $(\mathrm{P})$ e mais três amostras codificadas, em que uma delas era novamente o padrão. As amostras foram avaliadas por 20 julgadores não treinados, que eram alunos e funcionários da PUCPR, com idade igual ou superior a 18 anos, alfabetizados e capazes de manifestar o consentimento para a participação desta análise. Os doces de leite foram servidos em copos de plásticos descartáveis de $50 \mathrm{~mL}$, devidamente codificados e apresentados de forma casualizada. Foi oferecida água mineral para fazer o branco entre as amostras e para a limpeza do palato.

\section{Análise estatística}

A partir dos resultados da análise sensorial foi calculada, por análise de variância (ANOVA), a diferença significativa entre as três amostras de doce de leite, em nível de $5 \%$. A composição centesimal das amostras de doce de leite foi determinada pela média das triplicatas. 


\section{RESULTADOS}

Utilizando a Equação 1, constatou-se que o grau de hidrólise da lactose foi de 100\%, obtida no tempo de 6 horas, na concentração de $0,8 \mathrm{~g}$ de $\beta$-galactosidase por litro de leite. Segundo Perrone (2007), é necessário um controle constante da variação do índice crioscópico do leite, analisando-se, indiretamente, o grau de hidrólise da lactose.

O método de quantificação do grau de hidrólise da lactose pela medida do índice crioscópico utilizada na Equação 1 tem sido empregado pelas indústrias de laticínios como uma metodologia rápida (leitura inferior a 5 minutos) e eficiente para estimar o grau de hidrólise e a atividade da $\beta$-galactosidase em leite para elaboração de produtos lácteos com teor reduzido de lactose. O princípio desse método baseia-se nas mudanças das propriedades físicas do leite quanto ao abaixamento do ponto de congelamento (índice crioscópico), à pressão osmótica e à rotação ótica pela ação da enzima $\beta$-galactosidase sobre a lactose com produção de monossacarídeos (MAHONEY, 1985).

Tecnologicamente, uma atenção especial deve ser dada ao controle do grau de hidrólise da lactose pela enzima $\beta$-galactosidase, uma vez que algumas modificações são evidenciadas em decorrência dessa hidrólise, como a intensificação da reação de Maillard, aumento ligeiro da viscosidade e do sabor adocicado do produto (PERRONE, 2007).

Comparando-se os valores médios de umidade, gordura, proteína, carboidratos e cinzas dos doces de leite produzidos com as duas enzimas com os valores médios estabelecidos pela Portaria $\mathrm{n}$. 354/1997 (BRASIL, 1997), verificou-se que os valores encontrados para os doces de leite foram bastante similares aos requeridos pela legislação brasileira (Tabela 1).

TABELA 1 - Comparação dos resultados de composição centesimal das amostras de doce de leite tratados com $\beta$-galactosidase e o estabelecido pela Portaria nº 354/1997 do Ministério da Agricultura Pecuária e Abastecimento

\begin{tabular}{|c|c|c|c|}
\hline $\begin{array}{c}\text { Composição } \\
\text { Centesimal (g/100g) }\end{array}$ & $\begin{array}{c}\text { Doce de Leite } \\
\text { Enzima Prozyn* }\end{array}$ & $\begin{array}{c}\text { Doce de Leite } \\
\text { Enzima Novozymes* }\end{array}$ & $\begin{array}{l}\text { Portaria } \text { n }^{\circ} 354 / \\
1997 \text { do MAPA }\end{array}$ \\
\hline Umidade & 27,8 & 26,0 & máximo 30,0 \\
\hline Extrato Seco Total & 72,2 & 74,0 & mínimo 70,0 \\
\hline Gordura & 7,4 & 6,3 & 6,0 a 9,0 \\
\hline Proteína & 8,0 & 9,3 & mínimo 5,0 \\
\hline Carboidratos & 55,1 & 56,6 & - \\
\hline Cinzas & 1,7 & 1,8 & máximo 2,0 \\
\hline
\end{tabular}

* Produção a partir de leites tratados previamente com enzimas â-galactosidases de diferentes marcas comerciais

Os doces de leite produzidos com as enzimas Prozyn e Novozymes apresentaram, respectivamente, $72,2 \%$ e $74,0 \%$ de sólidos totais. Valores similares foram encontrados por Brasholanda (1991), que recomenda um teor médio de 70,0\% de sólidos totais para o doce de leite pastoso.

Os valores médios de $\mathrm{pH}$ encontrados para as amostras de doce de leite padrão, com a enzima Prozyn e com a Novozymes foram 6,0, 5,7 e 5,8, respectivamente. Observou-se neste estudo que os doces de leite produzidos com as duas marcas comerciais de $\beta$-galactosidase apresentaram coloração muito similar, embora mais escura quando comparado à coloração do doce de leite padrão. Sabe-se que velocidade máxima da reação de Maillard ocorre entre o pH 6,0 e 7,0 e é intensificada pelo aumento do grau de hidrólise da lactose, que resulta numa maior disponibilidade de açúcares redutores (PAVLOVIC et al., 1994). 
Os resultados da análise sensorial obtidos por ANOVA revelaram que os provadores não detectaram diferença significativa, em nível de 5\%, entre as amostras de doce de leite_padrão e com as enzimas Prozyn e Novozymes, em relação ao atributo sabor do produto. Esses resultados indicam que a ação das duas enzimas comerciais sobre a lactose não alterou significativamente o sabor das amostras de doce de leite. Resultados similares foram encontrados por Reasoner et al. (1981), que aplicaram o teste sensorial de comparação múltipla e não encontraram diferença significativa, em nível de 5\%, entre o leite com teor reduzido de lactose e leite desnatado comercial.

Com relação aos valores médios de lactose obtidos, tanto com o doce de leite produzido com a enzima Prozyn como o produzido com a enzima Novozymes foram inferiores ao limite de quantificação, ou seja, valores inferiores a $0,5 \mathrm{~g} / 100 \mathrm{~g}$ de lactose. Esses resultados indicam que a ação da $\beta$-galactosidase das duas marcas comerciais (Prozyn e Novozymes) foi eficiente na redução desse dissacarídeo no doce de leite. Conforme a Portaria n. 29/1998 (BRASIL, 1998) os alimentos elaborados especialmente para atender às necessidades de portadores de intolerância à ingestão de dissacarídeos e/ou portadores de erros inatos do metabolismo desses carboidratos devem atender ao máximo de 0,5 $\mathrm{g}$ do nutriente em restrito, por $100 \mathrm{~g}$ ou $100 \mathrm{~mL}$ do produto a ser consumido.

Apesar da recomendação diária de ingestão de lactose ser inferior a $12 \mathrm{~g}$ de lactose, que deve ser preferencialmente dividida entre as refeições, os indivíduos intolerantes frequentemente evitam leite e derivados, o que pode levar à inadequação nutricional, particularmente quanto à ingestão de cálcio (LOMER et al., 2008). Estudos realizados por Carroccio et al. (1998) constataram que a ingestão de cálcio em indivíduos intolerantes à lactose $(500 \mathrm{mg})$ foi significativamente menor que as recomendações diárias (800-1000 mg/dia), o que constitui fator de risco para o desenvolvimento da osteoporose. Sabese que a baixa ingestão de cálcio durante a adolescência e a fase adulta tem um importante impacto na densidade óssea. Apesar dos determinantes genéticos e biológicos da intolerância à lactose e osteoporose parecerem distintos, existe uma evidência que a prevalência de osteoporose é aumentada entre os indivíduos intolerantes à lactose, devido, provavelmente, à baixa ingestão de cálcio (JACKSON; SAVAIANO, 2001; BUCHOWSKI et al., 2002).

Ressalta-se, portanto, a importância de oferecer aos indivíduos intolerantes à lactose produtos lácteos com teor reduzido de lactose.

\section{CONCLUSÃO}

O grau de hidrólise total da lactose presente no leite, na concentração de $0,8 \mathrm{~g}$ $\beta$-galactosidase por litro de leite foi alcançado em 6 horas. O método baseado no índice crioscópico demonstrou ser eficiente para estimar o grau de hidrólise da lactose no leite.

A ação da enzima $\beta$-galactosidase pelas duas marcar comerciais não causou alteração significativa no sabor do doce de leite, em nível de 5\%, quando comparadas ao padrão.

Os doces de leite produzidos com as duas marcas de enzimas comerciais apresentaram níveis de lactose inferiores ao limite de quantificação $(\leq 0,5 \%)$, podendo ser considerados um alimento para fins especiais, devido ao teor reduzido de lactose.

\section{REFERÊNCIAS}

ASSOCIATION OF OFFICIAL ANALYTICAL CHEMISTS - AOAC. Official methods of analysis of the Association of Official Analytical Chemists. 17th ed. Gaithersburg: Aspen, 2000.

BRASIL. Ministério da Agricultura e do Abastecimento, Secretaria de Defesa Agropecuária, Departamento de Inspeção de Produtos de Origem Animal. Portaria n. 354, de 4 de setembro de

Rev. Acad., Ciênc. Agrár. Ambient., Curitiba, v. 7, n. 4, p. 375-382, out./dez. 2009 
1997. Regulamento Técnico para Fixação de Identidade e Qualidade de Doce de Leite. Diário Oficial [da] Republica Federativa do Brasil, Brasília, DF, 8 set. 1997. Seção 1, p. 19685. Disponível em: <http://e-legis.anvisa.gov.br/leisref/public/showAct.php?id=23441\&word $>$. Acesso em: 30 nov. 2009.

BRASIL. Ministério da Saúde, Agência Nacional de Vigilância Sanitária. Portaria n. 29, de 13 de janeiro de 1998. Regulamento Técnico para Fixação de Identidade e Qualidade de Alimentos para Fins Especiais. Diário Oficial [da] Republica Federativa do Brasil, Brasília, DF, 30 mar. 1998. Disponível em: < http://e-legis.anvisa.gov.br/leisref/public/showAct.php?id=17213>. Acesso em: 30 nov. 2009.

BRAShOlAndA S. A. Doce de leite: processo contínuo. Alimentos \& Tecnologia, ano 3, n. 38, p. 63-64, 1991.

BUCHOWSKI, M. S. et al. Dietary calcium intake in lactose maldigesting intolerant and tolerant African-American women. Journal of the American College of Nutrition, Cambridge, v. 21, n. 1, p. 47-54, 2002.

BULHÕES, A. C. et al. Correlation between lactose absorption and the C/T-13910 and G/A22018 mutations of the lactase-phlorizin hydrolase (LCT) gene in adult-type hypolactasia. Brazilian Journal of Medical and Biological Research, Ribeirão Preto, v. 40, n. 11, p. 1441-1446, 2007.

CASÉ, F. et al. Produção de leite de soja enriquecido com cálcio. Ciência e Tecnologia de Alimentos, Campinas, v. 25, n. 1, p. 86-91, 2005.

CARROCCIO, A. et al. Lactose intolerance and self-reported milk intolerance: relationship with lactose maldigestion and nutrient intake. Journal of the American College of Nutrition, Stanford, v. 17 , n. 6, p. 631-636, 1998

CUNHA, L. R.; SOARES, N. F. F. Desenvolvimento e avaliação de embalagem ativa com incorporação de lactase. Ciência e Tecnologia de Alimentos, Campinas, v. 27, p. 23-26, 2007. Suplemento 1.

DUTCOSKY, S. D. Análise sensorial de alimentos. 2. ed. Curitiba: Champagnat, 2007.

INTERNATIONAL DAIRY FEDERATION. Determination of the solids content of cheese and processed cheese. Bruxelas: FIL/IDF, 1982.

JACKSON, K. A.; SAVAIANO, D. A. Lactose maldigestion, calcium intake and osteoporosis in African-American, Asian-Americans, and Hispanic-Americans. Journal of the American College of Nutrition, Stanford, v. 20, n. 2, p. 198S-207S, 2001.

LOMER, M. C. E. et al. Review article: lactose intolerance in clinical practice: myths and realities. Alimentary Pharmacology and Therapeutics, London, v. 27, p. 93-103, 2008.

MAHONEY, R. R. Modification of lactose and lactose-containing dairy products with $\beta$-galactosidase. In: FOX, P. F. Developments in dairy chemistry. London: Elsevier, 1985. p. $69-107$.

PAVLOVIC, S. Maillard reaction during the processing of 'Doce de leite'. Journal of the Science of Food and Agriculture, New York, v. 66, n. 2, p. 129-132, 1994.

PEREIRA-FILHO, D.; FURLAN, S. A. Prevalência de intolerância à lactose em função da faixa etária e do sexo: experiência do Laboratório Dona Francisca, Joinville (SC). Revista Saúde e Ambiente, Joinville, v. 5, n. 1, p. 24-30, 2004. 
PERrone, I. T. Tecnologia de fabricação de doce de leite. Informe Agropecuário, Belo Horizonte, v. 28, n. 238, p. 67-74, 2007.

PRETTO, F. M. et al. Má absorção de lactose em crianças e adolescentes: diagnóstico através do teste de hidrogênio expirado com o leite de vaca como substrato. Jornal de Pediatria, Porto Alegre, v. 78, n. 3, p. 213-218, 2002.

REASONER, J. et al. Clinical studies with low-lactose milk. The American Journal of Clinical Nutrition, Stanford, v. 34, p. 54-60, 1981.

SPARVOLI, A. C. Má absorção de lactose do adulto em uma população nordestina. Campinas: Ed. da Unicamp, 1989.

SUAREZ, F. L.; SAVAIANO, D. A. Diet, genetics, and lactose intolerance. Food Technology, Chicago, v. 51, n. 3, p. 74-76, 1997.

TÉO, C. R. P. A. Intolerância à lactose: uma breve revisão para o cuidado nutricional. Arquivos de Ciências da Saúde Unipar, Umuarama, v. 6, n. 3, p. 135-140, 2002.

UGGIONI, P. L.; FAGUNDES, R. L. M. Tratamento dietético da intolerância à lactose infantil: teor de lactose em alimentos. Higiene de Alimentos, São Paulo, v. 21, n. 140, p. 24-29, 2006.

Recebido: 10/08/2009

Received: 08/10/2009

Aprovado: $18 / 08 / 2009$

Approved: 08/18/2009

Rev. Acad., Ciênc. Agrár. Ambient., Curitiba, v. 7, n. 4, p. 375-382, out./dez. 2009 